\title{
IMPLEMENTASI SISTEM SIARAN FM STEREO PLUS DATA-TEXT SCA (SUBSIDIARY COMMUNICATION AUTHORIZATION)
}

\author{
Suryo Novantara ${ }^{1}$, Heroe Wijanto ${ }^{2}$, Basuki Rahmat ${ }^{3}$ \\ Jurusan Teknik Elektro Sekolah Tinggi Teknologi Telkom, Bandung \\ 1mail@snovantara.port5.com, ${ }^{2}$ hrw@stttelkom.ac.id, ${ }^{3}$ bas@stttelkom.ac.id
}

\begin{abstract}
Abstrak
Dengan ditertibkannya frekuensi siaran FM (Frequency Modulation) dalam spasi kanal $200 \mathrm{kHz}$, maka suatu sinyal siaran FM stereo yang hanya memerlukan lebar-pita frekuensi $112 \mathrm{kHz}(2 \times 56 \mathrm{kHz}$ multipleks pita-dasar FM stereo termodulasi secara narrow band FM) akan memberikan ruang spektral sisa selebar sekitar $94 \mathrm{kHz}$ pada setiap spasi kanal. Penyisipan informasi lain pada ruang sisa spasi kanal tersebut biasa disebut SCA (Subsidiary Communication Authorization), yang bertujuan untuk meningkatkan efisiensi penggunaan alokasi spektral FM.

Penelitian ini mengusulkan penyisipan informasi berupa sinyal Data-Text digital termodulasi FSK (Frequency Shift Keying) sebagai fasilitas siaran tambahan. Informasi Data-Text diperoleh dari deretan kode biner serial berkecepatan 1200 bps yang dibangkitkan dari port RS-232 komputer. Sinyal FSK Data-Text tersebut dimodulasikan ke subcarrier $67 \mathrm{KHz}$ untuk selanjutnya digabungkan dengan sinyalsinyal multipleks audio stereo. Seluruh sinyal komposit dipancarkan dalam modulasi narrow-band FM dengan frekuensi carrier sesuai alokasi siaran FM 88 - 108 MHz. Sinyal tambahan ini perlu dijaga agar tidak terjadi tumpang-tindih spektral dengan sinyal matriks audio stereo melalui BPF (Band Pass Filter) pada frekuensi tengah $67 \mathrm{kHz}$ dan bandwith $13,4 \mathrm{kHz}$. Untuk proses demodulasi sinyal FSK-Data-Text SCA dapat digunakan rangkaian PLL (Phase-Locked Loop). Untuk tampilan Data-Text digunakan LCD.
\end{abstract}

Kata kunci : SCA, multipleks audio stereo, FSK-Data-Text, narrow band FM, LCD

Abstract

As the frequency allocation of FM (Frequency Modulation) broadcasting services has been regulated in $200 \mathrm{kHz}$ channel spacing arrangement, a stereophonic FM broadcasting signal with $112 \mathrm{kHz}(2 \times 56$ kHz multiplexed FM stereo base band modulated in narrow-band FM) bandwidth will give a $94 \mathrm{kHz}$ remainder in each channel spacing. Inserting another information in the remainder of channel spacing, usually named SCA (Subsidiary Communication Authorization), will increase efficiency of the FM spectral allocation.

The inserted information proposed in this research is the FSK (Frequency Shift Keying) modulated Data-Text service signal as an additional broadcasting facility. The Data-Text information is $\mathbf{1 2 0 0}$ bps serial binary code sequence generated by RS-232 computer port. The FSK Data-Text is modulated to $67 \mathrm{kHz}$ and combined with stereo multiplexed audio signal. The all of composite signal is transmitted in narrow band FM modulation on a carrier FM broadcasting service allocation between $88-108 \mathrm{MHz}$. This signal needs filtering by a BPF (Band Pass Filter) which has $13,4 \mathrm{kHz}$ bandwidth on $67 \mathrm{kHz}$ centre frequency to avoid overlapping with stereo matrix audio signal. The SCA FSK-Data-Text signal could be demodulated using a PLL (Phase-Locked Loop) circuit. An LCD is used to display the Data-Text.

Keywords: SCA, stereo multiplexed audio, FSK-Data-Text, narrow band FM, LCD

\section{Pendahuluan}

Semakin meningkatnya kebutuhan informasi aktual pada masyarakat saat ini, disertai mobilitas yang tinggi, membutuhkan perangkat yang bisa menyediakan informasi real time namun murah dan portable. Penambahan fasilitas Data-Text pada perangkat radio penerima siaran FM merupakan satu alternatif untuk menjawab persoalan ini.

Dengan ditambahkannya fasilitas tampilan Data-Text, berbagai informasi dapat ditampilkan tanpa mengganggu informasi audio yang sedang disiarkan. Pendengar bisa menikmati kejernihan suara radio FM-nya sambil membaca informasi terbaru pada tampilan layar LCD (Liquid Crystal Display). Pada penelitian ini, perangkat penerima
Data-Text dirancang untuk dapat ditambahkan pada semua jenis perangkat radio penerima FM, baik stereo maupun mono, baik yang baru maupun tua.

\section{Sistem SCA}

2.1. Layanan-Layanan SCA

Sebenarnya default cara penggunaan perangkat penerima siaran radio FM "hanya untuk didengar" dan "tidak untuk dilihat". Namun dengan pengelolaan kandungan informasi yang baik, maka tambahan informasi Data-Text akan menyebabkan perangkat penerima siaran radio FM menjadi menarik pula untuk dilihat. Termasuk dalam situasi tertentu, seperti pada perangkat penerima radio FM 
yang dipasang di mobil dan sedang dikendarai pada kondisi lalu lintas jalan yang mengalami kemacetan.

Pengguna dapat memperoleh berbagai informasi aktual, seperti perkembangan harga saham dan valuta asing, berita ekonomi politik dan sosial, berita olah raga, jadwal penerbangan, bursa jual beli barang, lowongan pekerjaan, atau acara-acara hiburan. Dapat juga kandungan Data-Text merupakan informasi yang terkait dengan programa radio yang sedang disiarkan, misalnya lirik lagu yang sedang diputar, daftar request lagu, ataupun kuis interaktif.

Secara umum, sinyal SCA berisikan salah satu dari layanan-layanan berikut:

\section{a. Background Music (Musik Latar)}

merupakan layanan yang paling banyak dijumpai pada penggunaan SCA, yaitu stasiun radio mengirimkan musik tambahan secara terusmenerus pada band SCA dan tidak pernah disela oleh penyiar ataupun iklan.

b. Radio Reading Services (Berita Cetak)

untuk membantu para tuna netra untuk mengetahui informasi-informasi dari koran, majalah, buku, dan media cetak lainnya yang dibacakan oleh operator layanan ini.

c. Foreign Language Services (Bahasa Asing)

ditujukan agar pengguna dapat dengan mudah memahami apa yang disampaikan oleh penyiar. Layanan semacam ini mirip dengan layanan duabahasa (bilingual) pada siaran televisi.

d. Data Transmissions (Pengiriman Data)

mengirimkan beragam informasi data digital: data pasar saham (stock market data), berita kejadian terbaru (breaking news), pengontrol stasiun pengulang (FM Repeater/Translator Station Commands), peringatan bahaya (Early Alert System - EAS), dan sebagainya. Pada penerima harus dilengkapi decoder untuk mendapatkan informasi yang diinginkan.

Beberapa referensi menyebutkan bahwa layanan informasi tambahan SCA dapat ditempatkan pada frekuensi $67 \mathrm{KHz}$ dan atau $92 \mathrm{KHz}$ pada base band sistem $\mathrm{FM}^{[9]}$. Pada penelitian ini hanya akan digunakan frekuensi $67 \mathrm{kHz}$. Layanan serupa sudah diterapkan untuk pengiriman data VoiceMail ke pelanggan melalui stasiun pemancar radio $\mathrm{FM}^{[1]}$.

\subsection{Pembangkitan Sinyal Data-Text SCA.}

Sinyal SCA (Subsidiary Communications Authorization) adalah sinyal subcarrier tambahan yang dipancarkan bersama dengan sinyal informasi utama dari suatu pemancar FM. Gambar 1 memperlihatkan sinyal pita-dasar komposit FM stereo dengan informasi SCA.

Pada frekuensi $20 \mathrm{~Hz}$ sampai dengan $15 \mathrm{kHz}$ terdapat sinyal informasi audio utama, yang merupakan hasil penjumlahan sinyal audio kanan dan kiri (L+R). Pada frekuensi $19 \mathrm{kHz}$ terdapat pilot tone yang dimanfaatkan oleh perangkat penerima siaran FM untuk demodulasi sinyal tambahan stereo (stereo subcarrier). Stereo subcarrier ini berada pada frekuensi $23 \mathrm{kHz}$ sampai dengan $53 \mathrm{kHz}$ yang mengandung informasi selisih antara audio kanan dan kiri (L-R) yang dimodulasikan secara AMDSB-SC (Amplitude-Modulation Double-Side-Band Suppressed-Carrier). Pada frekuensi $57 \mathrm{kHz}$ terdapat informasi RDS (Radio Data System). Sedangkan SCA subcarrier ditempatkan pada frekuensi $67 \mathrm{kHz}$ dan $92 \mathrm{kHz}^{[9]}$. Kedua pita SCA ini dapat digunakan salah satu maupun keduanya.

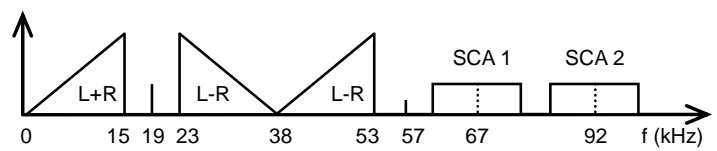

Gambar 1. Sinyal Komposit FM Stereo Plus SCA

Multipleks pita-dasar stereo FM (pita-dasar $\mathrm{L}+\mathrm{R}$, sisi ganda $\mathrm{L}-\mathrm{R}$ pada subcarrier $38 \mathrm{kHz}$, dan pilot tone $19 \mathrm{KHz}$ ) merupakan teknik pengolahan sinyal audio standar yang dilakukan untuk menjamin kompatibilitas sinyal siaran agar dapat diterima oleh baik oleh perangkat penerima FM monophonic maupun oleh penerima FM stereophonic.

\section{Implementasi Sistem SCA}

\subsection{Pemancar FM Plus Data-Text SCA}

Penambahan sinyal SCA yang mengandung informasi Data-Text ke dalam sistem pemancar FM stereo dilakukan oleh SCA Data-Text Generator. Informasi digital Data-Text diperoleh dari port RS232 sebuah komputer yang kemudian disesuaikan oleh rangkaian $R S$-232 Voltage Converter, sehingga aman diterima oleh rangkaian modulator FSK.

\begin{tabular}{|c|c|}
\hline header & informasi \\
\hline $\mathrm{X} X \mathrm{X} X \mathrm{X} \times \mathrm{X}$
\end{tabular}

Gambar 2. Format Frame Data-Text 8 bit

Format frame Data-Text 8 bit dibagi menjadi dua blok, masing-masing terdiri dari 4 bit data, yaitu satu blok header dan satu blok informasi sebagaimana diperlihatkan pada Gambar 2. Adapun perhitungan penentuan bit-rate data yang ditransmisikan untuk layanan SCA ini adalah sebagai berikut :

- 8 topik berita, masing-masing topik maksimal 80 karakter. Jika setiap 16 karakter ditampilkan di LCD selama 2 detik, maka untuk 80 karakter ditampilkan dalam 10 detik, dan refresh data dilakukan 10 detik untuk setiap topik.

- Karakter total untuk 8 topik: $8 \times 80$ karakter $=640$ karakter 
- Tiap karakter terdiri 8 bit, masing-masing dikirimkan dalam dua frame maka jumlah frame yang dibutuhkan adalah: $640 \times 2=1280$ frame.

- bit-rate minimum yang dibutuhkan adalah: $1280 \times 8$ bit $/ 10$ detik $=1024$ bps .

- Sebagai penyesuaian dengan kecepatan standar port serial komputer dan juga kemampuan chip modulator FSK, maka bit-rate data yang digunakan adalah 1200 bps.

Aliran Data-Text serial di atas dimodulasikan menurut standar BELL.202, yaitu secara FSK 1200 bps pada frekuensi mark $1200 \mathrm{~Hz}$ dan frekuensi space $2200 \mathrm{~Hz}$, sehingga menghasilkan sinyal FSK dengan lebar-pita $3,4 \mathrm{kHz}$. Pada penelitian ini, implementasi Modulator FSK menggunakan chip TCM3105 dari Texas Instruments.

Selanjutnya dilakukan proses modulasi SCA terhadap sinyal FSK Data-Text pada frekuensi subcarrier $67 \mathrm{kHz}$ untuk selanjutnya digabungkan dengan sinyal-sinyal multipleks audio stereo (pitadasar L+R, sisi ganda L-R pada subcarrier $38 \mathrm{kHz}$, dan pilot tone $19 \mathrm{KHz}$ ). Untuk implementasi modulator SCA digunakan chip VCO 566 dengan konstanta modulasi $k_{f}=6,6 \mathrm{kHz} /$ Volt. Dengan masukan berupa sinyal audio FSK yang memiliki lebar-pita dan frekuensi maksimum $f_{m}=3,4 \mathrm{kHz}$ dan amplitudo 0,5 Volt, maka lebar-pita sinyal SCA yang dihasilkan adalah $2 \times(0,5$ Volt $\times 6,6 \mathrm{kHz} /$ Volt $+3,4 \mathrm{kHz})=13,4 \mathrm{kHz}$, yang pada subcarrier $67 \mathrm{kHz}$ berarti menempati pita SCA 60,3 - 73,7 kHz.

Pada bagian akhir generator ini ditambahkan rangkaian BPF untuk meredam sinyal-sinyal yang berada di luar pita SCA, kemudian keluarannya digabungkan dengan sinyal multipleks FM stereo. Keseluruhan sinyal komposit akhirnya dipancarkan dalam modulasi narrow-band FM dengan frekuensi carrier sesuai alokasi siaran FM $88-108 \mathrm{MHz}$.

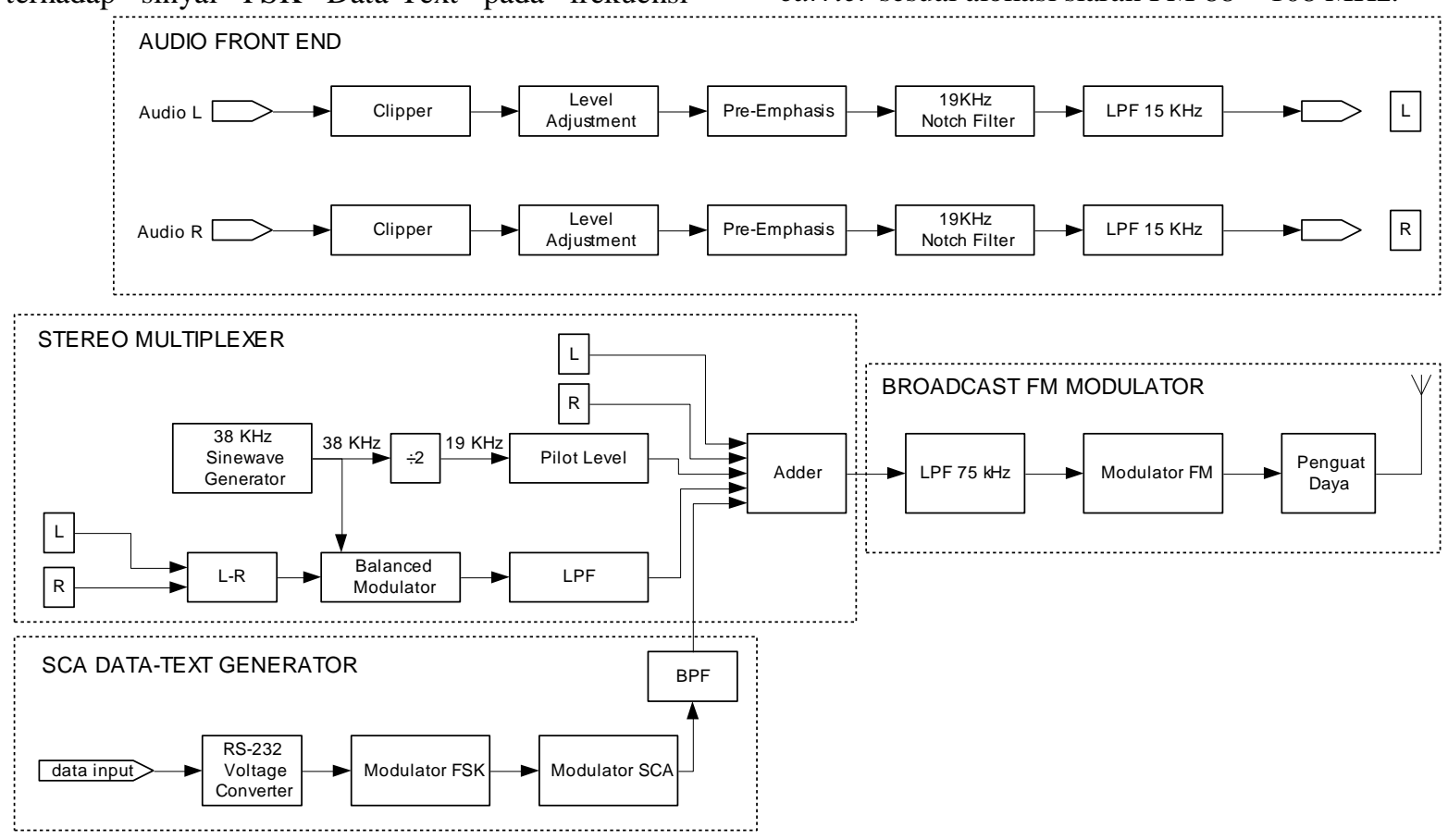

Gambar 3. Pemancar FM Stereo Plus Generator Data-Text SCA

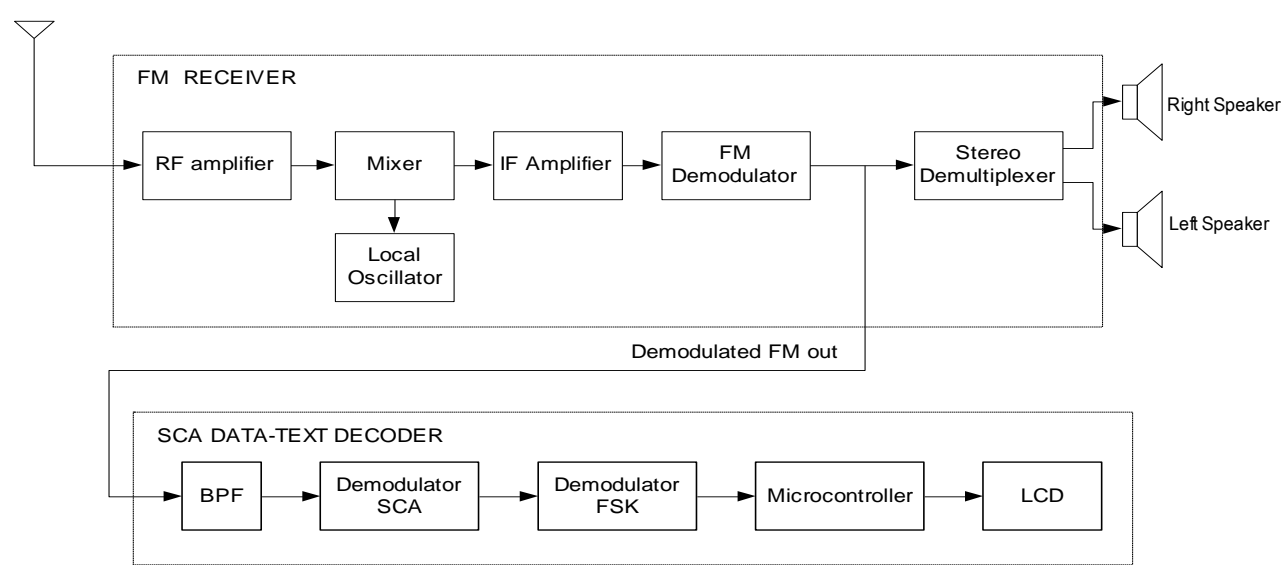

Gambar 4. Penerima FM Stereo Plus Dekoder Data-Text SCA 
Perancangan dan realisasi pemancar FM stereo perlu dilakukan dengan tepat sehingga menghasilkan kualitas suara yang sangat bagus. Keberhasilan perancangan dan realisasi sangat didukung oleh penggunaan rangkaian clipper, pembangkitan sinyal pilot tone yang bersih, dan penggunaan modulator FM yang stabil ${ }^{[5]}$. Secara skematik, perangkat Pemancar FM Stereo Plus Generator Data-Text SCA ditunjukkan di Gambar 3.

\subsection{Penerima FM Plus Data-Text SCA}

Perangkat tambahan (SCA Data-Text decoder) dipasang pada radio penerima siaran FM untuk mengekstraksi sinyal SCA Data-Text dari baseband FM, yaitu keluaran demodulator FM pada radio penerima, dan kemudian mengubahnya menjadi tulisan yang ditampilkan pada LCD. Proses pertama yang dilakukan adalah memisahkan sinyal SCA dari sinyal komposit stereo dengan menggunakan BPF. Kedua, mendemodulasi sinyal SCA ini dengan rangkaian yang menggunakan chip PLL 564 menjadi sinyal audio FSK. Ketiga, mendemodulasikan sinyal FSK dengan rangkaian yang menggunakan chip TCM3105 menjadi data digital. Dan yang terakhir, data digital ini diolah serta kemudian ditampilkan dalam bentuk text pada LCD. Secara skematik, perangkat Penerima Siaran FM Stereo Plus Dekoder Data-Text SCA diperlihatkan pada Gambar 4.

Liquid Crystal Display (LCD) sebagai layar peraga pada perangkat penerima dipadukan dengan menggunakan microcontroller PicMicro produksi Microchip. LCD dilengkapi dengan chip pengontrol HD44780 dari Hitachi sehingga menyederhanakan tugas microcontroller untuk mengendalikan $\mathrm{LCD}^{[3]}$.

LCD yang digunakan adalah WM-C1602M untuk menampilkan karakter 16 kolom $\times 2$ baris dengan format character set standard ASCII, sehingga kompatibel dengan character set yang dikirim dari Generator Data-Text. LCD ini dikendalikan oleh chip HD44780 yang mampu menampung sementara sebanyak 80 karakter untuk kemudian ditampilkan layar tampilan. Sebuah Microcontroller 8 bit diperlukan untuk mengolah sinyal SCA Data-Text agar dapat ditampilkan pada LCD adalah PIC16F84 dari Microchip yang dilengkapi memory jenis Flash/EEPROM dengan kemampuan In-Circuit Serial Programming (ICSP).

\section{Hasil Pengukuran dan Analisa}

Pada Gambar 5 terlihat terdapat empat komponen sinyal, yaitu sinyal audio $\mathrm{L}+\mathrm{R}$ pada frekuensi $20 \mathrm{~Hz}$ sampai dengan $15 \mathrm{kHz}$, sinyal pilot tone pada frekuensi $19 \mathrm{kHz}$, sinyal stereo L+R sisiganda subcarrier $38 \mathrm{kHz}$ di frekuensi $23-53 \mathrm{kHz}$ dan sinyal SCA FSK-Data-Text $67 \mathrm{kHz}$ pada frekuensi 62 - 72,75 kHz. Sinyal SCA Data-Text menempati bandwidth yang lebih kecil dari alokasi
$13,4 \mathrm{kHz}$ yang diberikan. Ini cukup bagus, karena guard band antara sinyal multipleks stereo FM dengan sinyal SCA Data-Text menjadi lebih jauh dan memperkecil overlapped antara kedua sinyal.

BPF SCA pada perangkat Decoder mengambil sinyal SCA ini sehingga didapatkan spektral sinyal yang tampak pada Gambar 6. Hasil pengukuran menunjukkan BPF SCA telah berhasil meredam sinyal yang berada diluar band SCA.

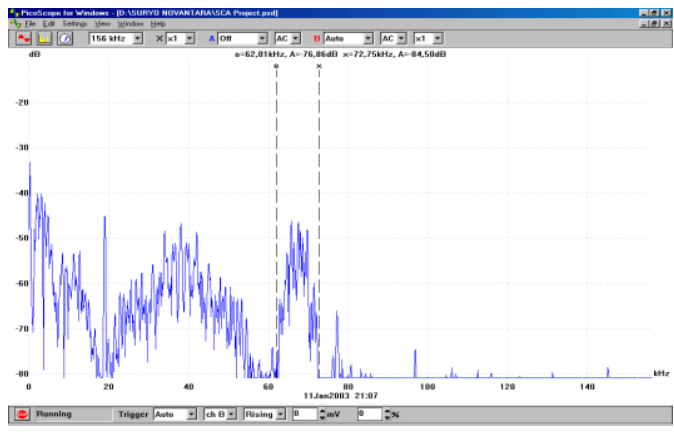

Gambar 5. Spektral Komposit Pita-Dasar Sinyal Multipleks Stereo FM Plus SCA

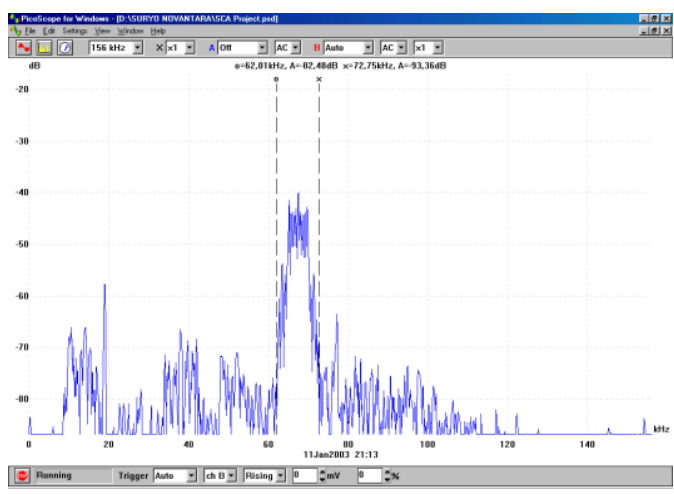

Gambar 6. Sinyal Ekstraksi SCA Keluaran BPF pada Dekoder di Perangkat Penerima

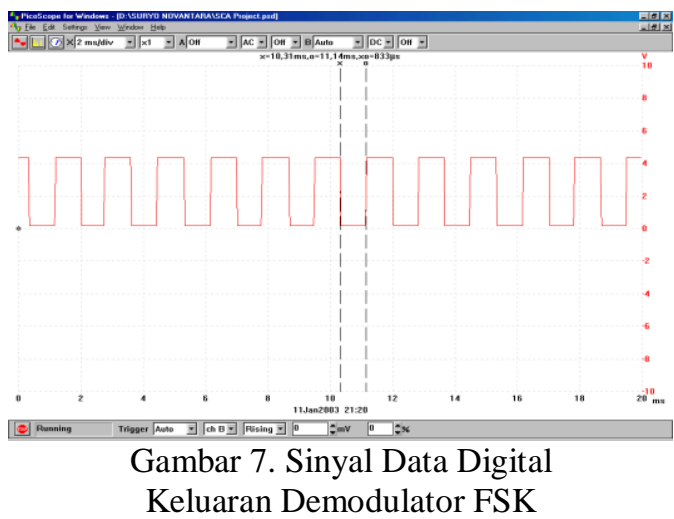

Sinyal hasil akhir dari Dekoder SCA Data-Text berupa sinyal digital yang tampak di Gambar 7, dengan bit-rate: $1200 \mathrm{bps}$, level sinyal 0 Volt untuk logic ' 0 ' dan 5 Volt untuk logic ' 1 '. Level ini sesuai untuk langsung diberikan ke port masukan pada microcontroller yang mengendalikan tampilan data ke layar LCD. 


\section{Kesimpulan dan Saran}

Dari hasil implementasi dan pengukuran Sistem Perangkat SCA, dapat disimpulkan bahwa sinyal audio masukan juga mengandung noise yang cukup mengganggu. Pengiriman data-text dengan kecepatan 1200 bps dapat dilakukan dengan bandwidth SCA selebar 13,4 kHz, pada frekuensi carrier $67 \mathrm{kHz}$. BPF SCA dengan frekuensi tengah sebesar $67 \mathrm{kHz}$ sangat membantu mengurangi overlapped antara sinyal SCA dengan sinyal subcarrier multipleks stereo. Demodulator SCA yang diimplemntasikan dari rangkaian PLL dapat mendemodulasi sinyal SCA dengan baik. Hal ini berdasarkan hasil pengukuran sinyal FSK yang dihasilkannya, sehingga sinyal FSK tersebut dapat di-recovery oleh demodulator FSK menjadi sinyal data digital tanpa adanya pelebaran maupun penyempitan bit data. Demodulator FSK mampu menghasilkan sinyal digital dengan baik walaupun sinyal FSK yang diterima dari demodulator SCA hanya mempunyai level maksimum $140 \mathrm{mVpp}$. Software sederhana yang ditanam pada perangkat SCA Data-Text decoder tidak mampu menangani adanya error pada data yang diterima. Proses pembuangan sinyal $19 \mathrm{kHz}$, pemotongan sinyal yang levelnya berlebihan, pre-emphasis, dan low pass filter pada Audio Front End Circuit mampu memperbaiki sinyal audio masukan sebelum diberikan pada rangkaian stereo multiplexer.

Untuk dapat dikembangkan menjadi suatu sistem yang lebih baik maka keterbatasan pada perancangan perlu diperbaiki dan beberapa masalah yang muncul dari hasil pengujian juga harus diatasi. Oleh karena itu perlu dilakukan penambahan blok noise reduction pada bagian Audio Front End Circuit untuk mengatasi adanya noise yang masuk bersamaan dengan sinyal audio. Perbaikan pada rangkaian LPF $15 \mathrm{kHz}, 55 \mathrm{kHz}$ dan $75 \mathrm{kHz}$ perlu dilakukan agar diperoleh filter yang akurat serta memperkecil noise yang dimunculkan oleh rangkaian filter itu sendiri. Nilai $k_{f}$ modulator FM perlu diperkecil, sehingga dapat menerima sinyal masukan dengan level yang lebih besar, namun tetap dapat dipertahankan kondisi narrowband. Hal ini bertujuan untuk menjaga nilai indeks modulasi $\beta$ dengan sinyal masukan yang tidak terlalu kecil, sehingga level sinyal dimunmgkinkan cukup jauh dari level noise. Stabilitas frekuensi carrier pada modulator FM masih dapat ditingkatkan, serta perlu penambahan gain penguat daya untuk memperluas jangkauan pancarnya. Bit rate data dapat ditingkatkan lagi agar lebih banyak informasi yang dikirimkan, serta memungkinkan adanya pengiriman gambar. Untuk itu LCD pada perangkat decoder sebaiknya digunakan LCD jenis graphic, sehingga selain untuk menampilkan informasi gambar yang diterima, juga untuk membuat tampilan lebih menarik. Dapat ditambahkan kemampuan error correction pada Dekoder SCA, sehingga memperkecil kesalahan data yang diterima. Pada perangkat Dekoder sebaiknya juga dilengkapi menu dan tombol browser sehingga lebih nyaman untuk digunakan, terutama apabila terdapat banyak topik berita yang diterima. Pengguna bisa memilih topik berita yang dibutuhkan dan juga bisa mengatur setting dari perangkat Dekoder dengan mudah. Pada perangkat Dekoder dapat ditambahkan port keluaran yang memungkinkan pengolahan data lebih lanjut.

\section{Daftar Pustaka}

[1] Clariti Telecommunications International, Ltd. White Paper: CLARICAST Digital Wireless VoiceMail System.

[2] Huelsman, L. P., 1993, Active and Passive Analog Filter Design: An Introduction. Singapore. McGraw-Hill.

[3] Illet, J., 1997, How to Use Intelligent LCDs, EPE Magazine.

[4] Kugelstadt, T., 2001, Excerpted from Op-Amps for Everyone. Chapter 16: Active Filter Design Techniques, Texas Instruments.

[5] Miller, G. M., 1993. Modern Electronic Communication, New Jersey, Prentice Hall.

[6] Peacock, C., 2001, Interfacing the Serial Port $R S$-232, BeyondLogic.

[7] Philips Semiconductors, 1992, Datasheet NE/SE566: Function Generator.

[8] Philips Semiconductors, 1994, Datasheet NE/SE564: Phase-locked loop.

[9] Roden, M. S., 1991, Analog and Digital Communication Systems, New Jersey, Prentice Hall International.

[10] Texas Instruments, 1995, Datasheet TCM3105: Single Chip Frequency-Shift-Keying Modem. 